\title{
O debate acerca do financiamento da educação na etapa municipal da Conae 2013/2014 de Curitiba-PR
}

\section{The debate about Financing of Education in 2013/2014 Curitiba Conae's Conference}

\author{
El debate sobre el financiamiento de la educación en la etapa \\ municipal de la Conae 2013/2014 de Curitiba-PR
}

Jokasta Pires Vieira Ferraz ${ }^{1}$ Ângelo Ricardo de Souza²

\begin{abstract}
Resumo
O artigo aborda os resultados dos debates na etapa municipal da Conferência Nacional de Educação de 2014 (Conae) em Curitiba, no que tange à temática do financiamento da educação, um dos sete eixos da Conae. O texto procura analisar as emendas aprovadas com participação dos diferentes segmentos da comunidade, na medida em que elas representam as ideias que predominaram no debate. O trabalho, ao final, ainda destaca a importância da atualização e constante vigilância no entorno deste temática, tendo em vista a sua centralidade na materialização da política educacional no Brasil.

Palavras-chave: Financiamento da Educação; Políticas Educacionais; Conae 2014.
\end{abstract}

\begin{abstract}
The article discusses the results of the debates in the municipal stage of the National Education Conference 2014 (Conae) in Curitiba, with respect to the topic of education funding, one of the seven axes of Conae. The paper analyzes the approved amendments with participation of different segments of the community, considering that they represent the ideas that prevailed in the debate. At the end, the work also emphasized the importance of updating and constant vigilance surrounding this theme, with the idea about its centrality in the materialization of educational policy in Brazil.

Keywords: Financing of Education; Educational policies; Conae 2014.
\end{abstract}

\section{Resumen}

El artículo analiza los resultados de los debates en la etapa municipal de la Conferencia Nacional de Educación 2014 (Conae) en Curitiba, con respecto al tema del financiamienton de la educación, uno de los siete ejes de la Conae. El artículo analiza las modificaciones aprobadas con la participación de diferentes sectores de la comunidad, en la medida en que representan las ideas que prevalecieron en este debate. El trabajo al final, también ha demostrado la importancia de la actualización y una vigilancia constante en torno a este tema, considerando su centralidad en la materialización de la política educativa en Brasil.

Palabras-clave: Financiamiento de la Educación; Políticas Educativas; Conae 2014.

1 Mestre em Educação. Professora da Rede Municipal de Ensino de Curitiba. E-mail: jokastaferraz@hotmail.com 2 Doutor em Educação. Professor e pesquisador do Núcleo de Políticas Educacionais e do Programa de Pós-Graduação em Educação da UFPR. E-mail: angelo@ufpr.br 


\section{Introdução}

Em 2013 no município de Curitiba foi organizada uma das etapas municipais da Conferência Nacional de Educação (Conae), entre tantas outras que aconteceram pelo Brasil. A conferência é formada pelo poder público e pela sociedade civil organizada, e teve como objetivos na etapa municipal: a) analisar o documento de referência nacional da Conae, b) discutir e estruturar propostas de emendas para este documento, c) encaminhar as emendas propostas e aprovadas em assembleia, para etapa estadual da Conae. As diversas conferências realizadas em todo país no ano de 2013 tiveram o intuito de contribuir para construção do novo Plano Nacional de Educação (PNE 2014-2014), que viria a ser aprovado em junho com a lei 13.005/2014.

A participação da sociedade na definição de metas para educação brasileira confere legitimidade ao PNE, bem como a sua elaboração articulada entre os entes federados une as metas às responsabilidades legais de cada ente, mas há também a inserção de interesse das instituições privadas nas discussões. Sendo assim, temos um espaço público de discussão e todo esse processo de participação pressupõe disputa de poder. Essas relações ficam expressas nas emendas aprovadas, pois a sua aprovação é condicionada à participação de segmentos que defendem determinadas ideias, e se posicionem sobre direitos e ações governamentais.

O objetivo deste texto é abordar o resultado deste debate na etapa municipal da Conae na cidade de Curitiba, procurando analisar as emendas aprovadas com participação dos diferentes segmentos da comunidade, na medida em que compreendemos que as emendas aprovadas representam as ideias que predominaram no debate, bem como os grupos que tiveram mais força para propor alterações.

Conforme o documento referência houve sete eixos para discussões: I) O Plano Nacional de Educação e o Sistema Nacional de Educação: organização e regulação; II) Educação e diversidade: justiça social, inclusão e direitos humanos; III) Educação, trabalho e desenvolvimento sustentável: cultura ciência, tecnologia, saúde e meio ambiente e desenvolvimento sustentável; IV) Qualidade da educação: democratização do acesso, permanência, avaliação, condições de participação e aprendizagem; V) Gestão democrática, participação popular e controle social; VI) Valorização dos profissionais da educação: formação, remuneração, carreira, e condições de trabalho; e o eixo VII) Financiamento da educação. O financiamento da educação é o eixo escolhido para análise proposta neste texto.

\section{Contextualizando o eixo VII: O financiamento da educação no Brasil}

Antes de analisar as emedas apresentadas no eixo VII, cabe apresentar brevemente a estrutura do financiamento da educação brasileira, pois é ela que é posta em discussão no referido eixo.

O financiamento da educação tem como principal fonte de recursos a vinculação da receita de impostos, com uma porcentagem mínima de investimento segundo o artigo 212 da Constituição Federal (CF) de 1988, que é organizada da seguinte forma,

A União aplicará, anualmente, nunca menos de dezoito, e os Estados, o Distrito Federal e os Municípios vinte e cinco por cento, no mínimo, da receita resultante de impostos, compreendida a proveniente de transferências, na manutenção e desenvolvimento do ensino (BRASIL, 1988).

Entretanto, podemos afirmar que é o investimento ${ }^{3}$ em educação ocorre proporcionalmente à arrecadação da união, estados, municípios e Distrito Federal. Sendo assim, a vinculação da receita de impostos age primeiro na regulamentação da aplicação dos recursos, o que vem a assegurar porcentagem mínima de investimento, entretanto, como grande parte dos municípios brasileiros possui baixa arrecadação, a vinculação, por si só, principalmente no caso de alguns entes federados municipais, não assegura valores significativos de investimento.

3 Quando usado 0 termo investimento, não estamos nos referindo ao conceito dado pela economia, na qual o termo significa uma aplicação que busca gerar maior produção ou retorno financeiro. Ao tratar o gasto em educação como investimento, vislumbramos sim, um retorno, porém este se traduz, de forma pedagógica na aprendizagem dos alunos e na qualidade da educação que é oferecida (FERRAZ, 2013, p.3). 
Todavia, com a competência supletiva e redistributiva atribuída à União, o governo federal tem o papel de equalizar a distribuição desses recursos, e um dos mecanismos para tal é a subvinculação da receita de impostos, efetivada pelo Fundo de Manutenção e Desenvolvimento do Ensino Fundamental e de Valorização do Magistério - Fundef, que teve vigência de 1998 até 2006, e pelo Fundo de Manutenção e Desenvolvimento da Educação Básica e de Valorização dos Profissionais da Educação - Fundeb, que foi iniciado em 2007 e tem vigência determinada até 2020.

A proposta da política de fundos é de redistribuição de recursos em âmbito estadual. Os que fundos promovem é uma subvinculação, que no caso do Fundef foi de $15 \%$ da receita de alguns impostos ${ }^{4}$, sendo que os recursos eram destinados apenas para o ensino fundamental. Com o advento do Fundeb, os recursos passaram a ser distribuídos para toda a educação básica e a subvinculação aumentou para 20\%, além de terem sido acrescidos alguns impostos à cesta ${ }^{5}$. Nesse modelo, a política de fundos pode ainda contar com a complementação da União em cada um dos fundos estaduais, quando estes não alcançam o valor mínimo anual por aluno determinado pela presidência da República.

A redistribuição dos recursos do Fundeb segue critérios estipulados anualmente, conforme resolução do Ministério da Educação, por exemplo, os fatores de ponderação aprovados em 2013 para o exercício de 2014, são:

I - creche em tempo integral:

a) pública: 1,30;

b) conveniada: 1,10 .

II - pré-escola em tempo integral: 1,30;

III - creche em tempo parcial:

a) pública: 1,00 ;

b) conveniada: 0,80 .

IV - pré-escola em tempo parcial: 1,00;

$V$ - anos iniciais do ensino fundamental urbano: 1,00;

$\mathrm{VI}$ - anos iniciais do ensino fundamental no campo: 1,15;

VII - anos finais do ensino fundamental urbano: 1,10;

VIII - anos finais do ensino fundamental no campo: 1,20;

IX - ensino fundamental em tempo integral: 1,30;

$X$ - ensino médio urbano: 1,25;

$X I$ - ensino médio no campo: 1,30;

XII - ensino médio em tempo integral: 1,30;

XIII - ensino médio integrado à educação profissional: 1,30;

XIV - educação especial: 1,20;

$X V$ - educação indígena e quilombola: 1,20;

$X V I$ - educação de jovens e adultos com avaliação no processo: 0,80; e

XVII - educação de jovens e adultos integrada à educação profissional de nível médio, com avaliação no processo: 1,20 (MEC, Resolução № 1, de 31 de dezembro de 2014).

4 Fundo de Participação dos Estados - FPE, Fundo de Participação dos Municípios - FPM, Imposto sobre Circulação de Mercadorias e Serviços - ICMS, Imposto sobre Produtos Industrializados, proporcional às exportações - IPIExp, Desoneração de Exportações (LC 87/96).

5 Imposto sobre Transmissão Causa Mortis - ITCM, Imposto sobre Propriedade de Veículos Automotores - IPVA, Imposto sobre Renda e Proventos incidentes sobre rendimentos pagos pelos Municípios, Imposto sobre Renda e Proventos incidentes sobre rendimentos pagos pelos Estados, Quota Parte de $\mathbf{5 0 \%}$ do Imposto Territorial Rural devida aos Municípios - ITR. 
Na redistribuição dos recursos eles são distribuídos conforme o número de matrículas e os fatores de ponderação para cada etapa e modalidade de ensino, conforme listado, o que significa que as matrículas são contabilizadas com pesos distintos, reconhecendo-se que alunos de etapas ou modalidades distintas necessitam de recursos distintos.

Para além dos recursos já citados, o financiamento da educação também conta com o salário-educação (contribuição social inteiramente vinculada à educação), cujos recursos são administrados pelo Fundo Nacional de Desenvolvimento da Educação (FNDE) . $^{6}$

A organização do financiamento da educação no Brasil pode passar por mudanças dentro de alguns anos, pois em 2020 encerra a vigência do Fundeb. É certo que apenas uma mudança muito drástica no modelo tributário brasileiro poderia dispensar a existência de uma política como esta, por isto, parece-nos que sem uma reforma tributária ampla, o Fundeb tende a continuar após esta data, o que implica em rediscussão e aprovação de novo prazo e, quiçá, novo modelo.

Ademais, o PNE aprovado pela lei $n^{\circ} 13.005$ de 2014, aponta para diversas demandas, dentre as quais, emblematicamente temos a aprovação da meta de ampliação do investimento em educação de maneira a atingir a porcentagem de $10 \%$ do PIB brasileiro.

Feita a descrição da estrutura brasileira de financiamento da educação pública, podemos olhar para o texto da Conae e para as emendas analisando sua relação com um panorama maior.

\section{O texto base da Conae 2014}

O texto base da Conae 2014, no que tange ao financiamento da educação, considera esta temática uma peça-chave na organização da educação brasileira:

0 financiamento da educação é elemento estruturante para a organização e o funcionamento das políticas públicas educacionais e, desse modo, para materialização do SNE. Embora não seja fator suficiente, é condição necessária para a universalização do direito à educação pública de qualidade (BRASIL, 2013, p. 84)

Compatível com esta importância, o texto mostra a centralidade do financiamento da educação na política educacional brasileira, evidenciando, por exemplo, o importante papel da Emenda Constitucional 59/2009, que inclui no texto constitucional brasileiro a obrigatoriedade, quando da elaboração do PNE, de uma meta que vincule o investimento público em educação a um percentual do Produto Interno Bruto (PIB) do país.

Contudo, o texto reconhece, mesmo que indiretamente, as dificuldades atreladas à temática do financiamento, em especial por conta do desenho federativo brasileiro, destacando que mesmo a CF reconhecendo o financiamento adequado da educação como um pilar na edificação de políticas mais efetivas, isto só se traduzirá na prática com a implementação de um SNE articulado, que integre e coloque em colaboração efetiva os entes federados.

Esta articulação remete à reflexão sobre a gestão dos recursos. Por isto, o texto base da Conae 2014 destaca a importância da gestão democrática e do controle social sobre os recursos públicos da educação. Por isto, o texto aponta para a importância dos Conselhos de Acompanhamento e Controle Social (CACS) do Fundeb, pois a eles cabe a tarefa de fiscalizar a aplicação do maior contingente de recursos públicos para a educação básica no país.

Na direção de uma melhor gestão, o texto propõe que os secretários de educação possam assumir a gestão dos recursos vinculados à educação, retirando o controle financista ou economicista que normalmente recai

6 Dentre os programas do FNDE que são financiados com este tributo estão: Alimentação escolar, Banda larga nas escolas, Biblioteca na escola (PNBE), Caminho da escola, Dinheiro direto na Escola (PDDE), Licitação e registro de preços, Livro didático (PNLD), PDE escola, Plano de Ação de Aceleração (PAC II), Plano de Ações Articuladas (PAR), Prestação de contas (Contas Online), Programa Um Computador por Aluno (Prouca), Proinfância, Prolnfo, Repasses diretos, Transporte escolar (PNATE).

Fonte: $h$ htp://www.fnde.gov.br/fnde/institucional/perguntasfrequentes/programas. Acesso em 15/08/2014 
sobre o modelo mais comum de organização das finanças públicas, no qual a mencionada gestão é feita pelo secretário da fazenda pública.

O texto, na sequência, é enfático na defesa da ampliação dos gastos públicos em educação, de maneira a se atingir pelo menos $10 \%$ do PIB, meta que acabou consagrada no texto aprovado do PNE, em junho de 20147. Nesta mesma direção, da necessidade de ampliação dos recursos, o texto avalia que os percentuais de vinculação orçamentária como definidos na CF não são suficientes para suprir as crescentes demandas educacionais brasileiras, nem mesmo para dar conta das demandas reprimidas ou mal atendidas historicamente.

Mas, para além da gestão e da ampliação dos recursos, o texto também defende a construção do Custo-Aluno Qualidade (CAQ) como elemento equalizador, tendo em vista a enorme desigualdade entre os entes federados e que, tendo em vista a proposta básica de $C A Q$, garante condições de qualidade para a educação brasileira.

Finalmente, o texto base da Conae 2014 apresenta um conjunto de proposições e estratégias, focalizando: a) a regulamentação do regime de colaboração entre os entes federados; b) redefinição do modelo de financiamento da educação, considerando a capacidade arrecadatória dos entes federados; c) ampliação dos investimentos públicos em educação, de maneira a atingir pelo menos 10\% do PIB; d) garantir novas fontes de financiamento da educação, bem como articular essas fontes e o novo PNE com as outras peças legais que incidem sobre o orçamento público brasileiro; e) ampliar o percentual de vinculação orçamentária para 25\% (União) e 30\% (Estados, Distrito Federal e Municípios), pelo menos; f) deixar de considerar os gastos com aposentadorias e pensões dos gastos como despesas com MDE; g) implementar o CAQi e construir o CAQ; h) reorganizar peças legais, como a LRF, para garantir ampliação das possibilidades de financiamento para a educação; i) alterar e melhorar a política de fundos ${ }^{8}$; dentre outras metas.

\section{Análise das emendas aprovadas}

Da documentação da etapa municipal da Conae, em Curitiba, foram disponibilizados para consulta as ementas aprovadas e estas foram organizadas em dois quadros, o quadro 1 contém as emendas aditivas, totalizando 33 emendas com 23 assuntos diversos. Cada número de referência diz respeito a uma emenda e o assunto do seu referido teor está descrito na coluna "conteúdo".

As emendas aditivas em maior número são as quem procuraram priorizar os recursos para a educação pública, reforçando sempre ao sugerir adicionar a expressão "educação pública" à construção do texto. Essa preocupação buscou assegurar que fosse contemplando o que a Lei de Diretrizes e Bases da Educação Nacional (LDB), Lei Federal 9394/96, não assegura, pois segundo seu artigo 70, considera-se como despesas com MDE, por exemplo, concessão de bolsas de estudo para alunos de escolas privadas. Assim, a leitura dos proponentes de tais emendas é de que o mencionado artigo dá espaço para que os recursos públicos não sejam unicamente investidos na educação pública.

O custo aluno-qualidade (CAQ) está presente em duas emendas e o custo aluno-qualidade inicial (CAQi), em uma, as quais reiteram a preocupação de que o financiamento deve assegurar qualidade e esta deve ser critério para execução dos recursos. A preocupação com o acompanhamento e controle dos recursos também é uma constante, por meio das ementas que tratam sobre o papel do ministério público, sobre a gestão democrática, bem como sobre conselhos e controle social.

Temáticas ligadas às diversidades (afrodescendentes, indígenas, quilombolas, povos e comunidades tradicionais, étnico-raciais e gênero) também permeiam o texto das emedas aditivas. De certa forma, podemos

7 Quando da elaboração do texto base da Conae 2014, o PNE ainda estava em tramitação e, portanto, não se sabia se o Congresso Nacional iria aprovar esta meta, e depois se a Presidenta iria ou não sancioná-la.

80 texto faz uma série de recomendações sobre como o Fundeb pode ser melhorado. 
considerar que se houve alguma necessidade de emendas aditivas é porque a temática deixou de ser contemplada da melhor forma no texto base, além disso, as aprovações destas emendas confirmam a demanda para se pensar e projetar políticas especificas de financiamento.

De maneira geral, as emendas aditivas parecem estar em consonância com as discussões em nível nacional, tendo em vista que vários dos assuntos estiveram presentes na etapa nacional da Conae, além de causarem polêmica na aprovação do PNE, como as questões relativas à igualdade de gênero.

\section{Quadro 1: Emendas aditivas - CONAE Curitiba}

\begin{tabular}{|c|c|c|c|}
\hline Emenda & Quantidade & Conteúdo & Referência \\
\hline & & $\begin{array}{l}\text { Afrodescendentes, indígenas, quilombolas, povos e } \\
\text { comunidades tradicionais e egressos da EJA }\end{array}$ & 502 \\
\hline & & $\mathrm{CAQ}$ & 479 e 480 \\
\hline & & Conselhos & 515 \\
\hline & & Controle social & 453 \\
\hline & & Desigualdades regionais e étnico-raciais & 495 \\
\hline & & Educação básica pública & 508 \\
\hline & & Educação profissional pública & 507 \\
\hline & & Educação pública & $\begin{array}{c}449,451,454,456,466,470,474 \\
475,476,481\end{array}$ \\
\hline & & Ensino superior e distribuição de recursos & 499 \\
\hline & & $\begin{array}{l}\text { Funbed, CAQi, EJA, creches e escolas de ed. especial } \\
\text { conveniadas }\end{array}$ & 488 \\
\hline & & Gestão democrática, controle social & 511.5 .4 \\
\hline \multirow[t]{11}{*}{ Aditiva } & \multirow[t]{11}{*}{33} & $\begin{array}{l}\text { Informatizar gestão considerando as especificidades dos } \\
\text { diferentes níveis, etapas e modalidades de educação. }\end{array}$ & 510 \\
\hline & & Manutenção de equipamentos públicos & 487 \\
\hline & & $\begin{array}{c}\text { Ministério público, Conselhos municipais de educação } \\
\text { deliberativos }\end{array}$ & 463 \\
\hline & & $\begin{array}{l}\text { Pesquisas que levem em conta relações assimétricas, étnico- } \\
\text { raciais e de gênero }\end{array}$ & 482 \\
\hline & & $\begin{array}{c}\text { Pós-graduação stricto sensu com politicas de acesso e } \\
\text { permanência para todos }\end{array}$ & 505 \\
\hline & & Pós-graduação stricto e lato & 503 \\
\hline & & Profissionais da educação & 485 \\
\hline & & Receitas e despesas por nível, etapa e modalidade & 518 \\
\hline & & Regime estatutário & 450 \\
\hline & & Todos os níveis, etapas e modalidade & 471 e 472 \\
\hline & & Transporte escolar e EJA & 491 \\
\hline
\end{tabular}

Fonte: Arquivos Conae Curitiba - Informações organizadas pelos autores, 2013. 
No segundo quadro, temos uma quantidade menor de emendas, porém algumas com grandes pretensões, abordando elementos que se diferem do que já é previsto em lei, como por exemplo, a desvinculação do pagamento dos trabalhadores da educação da folha de pagamento geral para efeitos dos cálculos dos gastos públicos estabelecidos pela Lei de Responsabilidade Fiscal (LRF), mas ao mesmo tempo elimina algum possível empecilho na valorização salarial dos trabalhadores.

Sobre a garantia do transporte escolar com recursos além dos destinados à MDE, parece haver nas emendas uma estratégia de assegurar recursos para além dos $25 \%$ vinculados constitucionalmente, entretanto, no caso do Paraná, existe uma normatização específica para a oferta do transporte escolar, que é o Provimento 1/99 do Tribunal de Contas do Paraná, que prevê regras claras para compra ou locação de veículos, conforme for mais econômico, ademais a aquisição de vales-transportes não se caracterizaria como transporte escolar, ou seja, regras para o bom o uso dos recursos existem, cabe refletir se maior controle social não melhoraria o uso do recurso.

Cabe também observar que já existem recursos para além dos $25 \%$ que são destinados ao transporte escolar, que é o Programa Nacional de Apoio ao Transporte do Escolar (Pnate), porém este é destinado especialmente a alunos moradores da zona rural. Com essas considerações, cabe refletir se a proposição da ampliação/melhoria do programa, com recursos do FNDE, não seria mais interessante do que indicar a desvinculação dos gastos com MDE, pois assim se tem diretrizes mais claras de organização e fontes de recursos.

Outra emenda interessante trata sobre os recursos do salário educação, propondo a ampliação da contribuição de 2,5\% para 3,5\% sobre a folha de pagamento. Esta proposta, se efetivada, apresentaria um ganho real para os programas e políticas gerenciados pelo FNDE, pois a integralidade desses recursos é destinada para educação.

A nova emenda apresentou a defesa da interrupção, em 2018, da transferência de benefícios para iniciativa privada. Esta emenda apoia as emendas aditivas sobre recursos públicos para a educação pública, entretanto tal ação, se de fato efetivada, impactaria em diversos programas federais consolidados, principalmente nos destinados ao ensino superior e técnico, além disso, as políticas de convênio existentes em grande parte na educação especial e infantil, também sofreriam com uma medida como esta. Uma estratégia coerente seria atrelar o cessamento dos recursos para instituições privadas com uma meta de atendimento dessa população pelo poder público em instituições públicas. Este é, de resto, um assunto complexo e que pautou, e ainda pautará por algum tempo, o debate nacional (e mesmo internacional) sobre educação, que é a relação públicoprivado. Parece-nos que, mesmo meritória, a emenda em tela não conseguiria se efetivar em prazo tão exíguo, particularmente na educação infantil e educação especial. Todavia, com um plano mais a longo prazo e, como mencionado, com metas de atendimento explícitas pelo poder público, parece possível se desenhar um futuro no qual o dinheiro público deixe de subsidiar as ações e instituições privadas na educação brasileira.

A emenda substitutiva sobre "estímulo e consulta aos PPPs, currículos, regimentos, planos de gestão", não tem relação direta com a estrutura do financiamento da educação, mas sim com o controle social. Os documentos que regem a organização da escola, de fato, são deixados de lado no cotidiano, mas a ciência dos mesmos, por parte dos profissionais e da comunidade é fundamental para o acompanhamento, fiscalização e intervenção quando necessário. A escola gere recursos que são destinados diretamente a ela, como, por exemplo, o dinheiro do Programa Dinheiro Direto na Escola (PDDE), do Mais-Educação, além de recursos próprios das Associações de Pais e Mestres (APM), sendo que a gestão desses recursos é com certeza mais efetiva na medida em que forem mais conhecidos os documentos norteadores do trabalho no ambiente escolar.

A última emenda que gostaríamos de comentar trata dos "Recursos para o desenvolvimento de políticas para ingresso de afrodescendentes e indígenas no magistério superior da rede pública de ensino", o ponto interessante desta proposição é prever a garantia de recursos e não somente implementação de políticas, demonstrando que o movimento social parece estar ampliando a sua ação, de maneira mais organizada, pois para além da defesa do princípio, está avaliando (e propondo) a materialização do princípio em políticas efetivas. 


\section{Quadro 2: Emendas CONAE Curitiba}

\begin{tabular}{|c|c|c|c|}
\hline Emenda & Quantidade & Conteúdo & Referência \\
\hline Supressiva parcial ou total & 1 & Fundo Social do pré sal & 478 \\
\hline \multirow{4}{*}{ Substitutiva } & \multirow{4}{*}{4} & Fundo Social do pré sal & 478 \\
\hline & & CAQ & 479 \\
\hline & & $\begin{array}{l}\text { LRF - desvincular as despesas com folha de pagamento dos trabalhadores } \\
\text { da educação aos limites de gastos }\end{array}$ & 483 \\
\hline & & Estimulo e consulta aos PPPs, currículos, regimentos, planos de gestão. & 511.5 .4 \\
\hline \multirow{5}{*}{ Nova emenda } & \multirow{5}{*}{5} & Garantia do transporte escolar com recursos além dos destinados a MDE & 2.13 .1 \\
\hline & & $\begin{array}{l}\text { Recursos para o desenvolvimento de politicas para ingresso de } \\
\text { afrodescendentes e indígenas no magistério superior da rede pública de } \\
\text { ensino }\end{array}$ & 3.14 .1 \\
\hline & & $\begin{array}{l}\text { Ampliar a oferta de educação pública superior, pois os programas federais } \\
\text { de subsidio não tem caráter permanente }\end{array}$ & 3.15 \\
\hline & & Cessamento dos benefícios para iniciativa privada até 2018 & 4.1.1 \\
\hline & & $\begin{array}{c}\text { Ampliação da contribuição do salário educação para } 3,5 \text { da folha de } \\
\text { pagamento }\end{array}$ & 520 \\
\hline
\end{tabular}

Fonte: Arquivos Conae Curitiba - Informações organizadas pelos autores, 2013.

\section{Conclusões}

Considerando o material disponibilizado, fruto da etapa municipal da Conae em Curitiba, obtivemos 33 emendas aditivas, 1 supressiva parcial ou total, 4 substitutivas e 5 novas emendas, no eixo VII- Financiamento da Educação.

Não foram aprovadas emendas com relação específica à educação infantil, mas também não temos a informação se emendas foram apresentadas e reprovadas pela assembleia. Considerando que em 2016 a obrigatoriedade do ensino passa a abranger todas as crianças e adolescentes dos 4 aos 17 anos, é estranho não ter havido emendas aprovadas sobre este tema, em particular considerando que a educação infantil não tem oferta universalizada no município de Curitiba.

Conferências se constituem em espaços democráticos, onde participam o poder público, a sociedade civil, os movimentos sociais, os representantes do setor privado, os trabalhadores da educação, dentre outros. Para cada emenda aprovada, podemos considerar a existência de grupos com ideias articuladas, que com maior ou menor grau de organização, conseguiram garantir na etapa municipal que o que consideram melhor para educação fosse debatido.

O momento agora, para o poder público e para a sociedade de Curitiba, com a aprovação do PNE 201420124, é da construção no novo Plano Municipal de Educação:

a grande questão para a sociedade e para os políticos é a seguinte: queremos ou não ter um PNE viável e coerente - com os sucedâneos Planos estaduais, Municipais e do Distrito Federal - para ser efetivamente cumprido? A experiência da lei $n^{0} 10.172$, de 2001, foi desastrosa. Simplesmente seus dispositivos foram ignorados nas leis orçamentárias da União e dos entes federados (MONLEVADE, 2011, p. 19)

Sem a articulação e consonância do PNE com os planos estaduais e municipais, é possível que boa parte do esforço realizado no plano nacional não se efetive. 
Mas, de outro lado, também é necessária muita vigilância e controle social. O município de Curitiba, como todo o Brasil, fez um esforço muito grande, necessário e construtivo, no processo da Conae 2014, buscando discutir ideias e apresentar propostas para o enfrentamento dos problemas históricos da educação em nosso país. A partir de agora, além do necessário debruçar-se sobre o plano municipal, é preciso que todos estejamos atentos às ações do Estado no cumprimento das metas do PNE, em particular as metas que dão materialidade mais concreta às ideias, que são as metas do financiamento da educação.

\section{Referências}

BRASIL. Constituição Federal de 1988. Disponível em http://www.planalto.gov.br/ccivil 03/constituicao/ constituicaocompilado.htm. Acesso em 01/dez/2014.

Lei de Diretrizes e Bases da Educação, Lei Federal 9.394/96. Disponível em http://www.planalto.gov. br/ccivil 03/leis/19394.htm. Acesso em 01/dez/2014.

Plano Nacional de Educação, Lei Federal 13.005/14. Disponível em http://www.planalto.gov.br/ ccivil_03/_Ato2011-2014/2014/Lei/L13005.htm. Acesso em 01/dez/2014.

Conae 2014: Documento Referência. Brasília, 2013. Disponível em http://conae2014.mec.gov.br/ images/pdf/doc referencia.pdf. Acesso em 01/dez/2014.

FERRAZ, J. P. V. Panorama do gasto-aluno nas redes estaduais e municipais brasileiras. Dissertação de mestrado (Mestrado em Educação). Curitiba: UFPR, 2013.

MONLEVADE, J. A. C. Percentual de recursos públicos para a educação: compromisso irrevogável do PIB. Jornal de Políticas Educacionais. v. 5, n. 9, jan-jun 2011, p. 11-19.

TRIBUNAL DE CONTAS DO PARANÁ. Provimento $\mathbf{n}^{\circ}$ 1, 1999. Disponível em http://www.tce.pr.gov.br/ acervo/1999/12/1000088.pdf. Acesso em 01/dez/2014.

Recebido em dezembro de 2014 - Aprovado em dezembro de 2014 